\title{
Pengaruh Model TGT Berbantu Media Pinball Terhadap Hasil Belajar Siswa
}

\author{
Bayu Kurniawan * \\ Jurusan Pendidikan Guru Sekolah Dasar, Universitas PGRI Semarang, Jawa Tengah, Indonesia
}

\author{
A R TICLEINFO \\ Article history: \\ Received 18 Desember \\ 2017 \\ Received in revised form \\ 30 Desember 2017 \\ Accepted 15 Januari 2018 \\ Available online 20 \\ Februari 2018 \\ Kata Kunci: \\ Model Pembelajaran \\ Kooperatif Tipe TGT, media \\ pinball, hasil belajar \\ Keywords: \\ Cooperative Learning Model \\ TGT type, pinball media, \\ learning outcomes..
}

\begin{abstract}
A B S T R A K
Pendidikan merupakan usaha sadar dan berencana untuk mewujudkan suasana belajar dan proses pembelajaran agar siswa secara aktif mengembangkan potensi dirinya untuk memiliki kekuatan spiritual keagamaan, pengendalian diri, kepribadian, kecerdasan, akhlak mulia, serta keterampilan yang diperlukan dirinya, masyarakat, bangsa dan negara. Dengan pembelajaran menggunakan model Kooperatif Tipe TGT berbantu media pinball diharapkan mampu mempengaruhi dan meningkatkan hasil belajarnya. Penelitian ini bertujuan untuk mendeskripsikan pengaruh model pembelajaran Kooperatif tipe TGT terhadap hasil belajar mata pelajaran Matematika kelas V SD N 03 pamutih dalam pembelajaran materi bangun ruang. Jenis penelitian ini adalah Pre-Eksperimental Design dengan model One-Group PretestPosttest Design. Teknik pengumpulan data menggunakan teknik pengumpulan data tes, observasi dan dokumentasi. Populasi penelitian adalah seluruh siswa kelas V SD N 03 Pamutih Kabupaten Pemalang tahun ajaran 2018-2019. Berdasarkan olah data menggunakan uji-t disimpulkan bahwa terdapat pengaruh model TGT berbantu media pinball terhadap hasil belajar siswa kelas V SD N 03 Pamutih. Hasil penelitian menunjukkan bahwa: pengaruh peningkatkan hasil belajar siswa setelah diberikan model TGT berbantu media pinball sebesar $23,3 \%$.
\end{abstract}

\section{A B S T R A C T}

Education is a conscious and planned effort to create a learning atmosphere and learning process so that students actively develop their potential to have religious spiritual strength, selfcontrol, personality, intelligence, noble character, and skills needed by themselves, society, nation and country. With learning using the Cooperative Type TGT model assisted by pinball media, it is expected to be able to influence and improve learning outcomes. This study aims to describe the influence of the Cooperative type TGT learning model on learning outcomes of Mathematics subjects in class $V$ SD N 03 pamutih in learning material building space. This type of research is Pre-Experimental Design with the One-Group Pretest-Posttest Design model. Data collection techniques use the technique of collecting test data, observation and documentation. The study population was all V grade students of SD N 03 Pamutih Pemalang Regency 2018-2019 academic year. Based on data processing using the t-test it was concluded that there was an effect of the TGT model assisted by pinball media on the learning outcomes of fifth grade students of SD N 03 Pamutih. The results showed that: the effect of increasing student learning outcomes after being given a TGT model assisted by pinball media was $23.3 \%$. 


\section{Pendahuluan}

Pendidik menurut UU RI No. 14 Tahun 2005 adalah profesional dengan tugas utama mendidik, mengajar, membimbing, mengrahkan, melatih, menilai, dan mengevaluasi siswa pada pendidikan anak usia dini jalur pendidikan formal, pendidikan dasar, dan pendidikan menengah. Sedangkan siswa adalah anggota masyarakat warga negara yang berusaha mengembangkan potensi diri melalui proses pembelajaran pada jalur pendidikan baik pendidikan formal maupun pendidikan nonformal, pada jenjang pendidikan dan jenis pendidikan tertentu. Oleh karena proses belajar merupakan suatu kegiatan yang melibatkan peran aktif antara pendidik dan siswa maka dari itu dibutuhkan suatu metode pembelajaran yang mampu memudahkan pendidik dalam menyampaikan materi dan mampu memudahkan siswa dalam menerima dan memahami materi yang diberikan sehingga hasil belajar siswa dapat meningkat.

Pada proses pembelajaran pendidik dalam menyampaikan materi kurang memperhatikan metode yang digunakan pendidik hanya menyampaikan materi yang sesuai dengan silabus, hal itu didapatkan ketika peneliti melakukan wawancara dengan pendidik. Pendidik mengungkapkan bahwa proses pembelajaran teori diberikan hanya 1-2 kali pertemuaan ketika menjelang mid semester sehingga proses belajar mengajar berjalan kurang efektif. Metode yang digunakan dalam proses belajar mengajar di SD N 03 Pamutih Kab. Pemalang masih menggunakan metode konvensional dan demonstrasi, sehingga siswa bersifat pasif dalam pembelajaran karena pendidik yang lebih banyak berperan aktif dalam kegiatan belajar mengajar.

Mata pelajaran Matematika merupakan mata pelajaran yang wajib diajarkan di Sekolah pada setiap jenjang pendidikan dan salah satu mata pelajaran yang penting bagi siswa untuk membentuk karakter, mental, serta pengetahuan dan pengalaman sehingga dapat diaplikasikan kedalam kehidupan sehari-hari karena dalam kehidupan tidak pernah lepas dari unsur Matematika. Pada taraf pendidikan Sekolah Dasar materi yang diajarkan dalam mata pelajaran Matematika masih bersifat dasar seperti penjumlahan, pengurangan, perkalian dan pembagian dengan tujuan menanamkan teori serta hitungan dasar untuk mempersiapkan pada jenjang yang lebih tinggi dan diaplikasikan pada kehidupan sehari-hari. Pentingnya Mata pelajaran Matematika pada Sekolah Dasar kelas tinggi, seharusnya menjadi pemicu siswa untuk menguasai mata pelajaran ini dengan maksimal, namun pada faktanya ketika peneliti melaksanakan observasi awal di SD Negeri 03 Pamutih ditemukan fakta bahwa mata pelajaran Matematika tergolong sulit dilihat dari hasil belajar siswa. Ditemukan bahwa siswa kelas V SD Negeri 03 Pamutih dalam mata pelajaran Matematika rata-rata nilai yang siswa ditemukan belum memenuhi Kriteria Ketuntasan Minimum (KKM) yaitu 70 dengan nilai rincian jumlah siswa 30 siswa, prosentase siswa yang memenuhi KKM sebanyak 33,33\% siswa dengan rat-rata 70, sedangkan yang belum tuntas KKM sebanyak 66,64\% siswa dengan nilai rata-rata 50. Sehingga rata-rata nilai dalam kelas V siswa SD Negeri 03 Pamutih yaitu 55 (belum memenuhi KKM).

Berkaitan dengan masalah diatas untuk mengatasi kebosanan siswa dalam belajar dan meningkatkan prestasi dalam proses belajar mengajar, maka peneliti ingin menerapkan medel pembelajaran TGT berbantu media pinball. Team games tournament menurut Qalbi dkk (2017:68) menyatakan bahwa model tipe cooperative learning tipe team games tournament adalah salah satu model pembelajaran kooperatif yang menjadikan siswa sebagai pusat kegiatan. Untuk itu model cooperative learning tipe team games tournament adalah salah satu model tipe cooperative yang mudah diterapkan dimana melibatkan aktivitas seluruh siswa sebagai pusat pembelajaran. Seperti yang kita ketahui bersama bahwa siswa tingkat Sekolah Dasar secara psikologis mereka cenderung lebih senang bermain. Jadi dengan memasukkan model pembelajaran berbasis team games tournament ini diharapkan siswa akan lebih termotivasi untuk mengikuti proses kegiatan belajar mengajar, agar dapat meningkatkan hasil belajar siswa. Model pembelajaran Team Games Tournament dalam penerapan mata pelajaran Matematika peneliti memerlukan suatu media pembelajaran agar dapat diterapkan sesuai dengan model pembelajaran ini. Karena media pembelajaran adalah suatu komponen penting dalam pembelajaran agar proses kegiatan belajar mengajar dapat berjalan dengan maksimal. Dalam hal ini peneliti akan mengembangkan media pembelajaran yang bernama Pinball. Secara bahasa Pinball adalah bola yang memantul, kemudian secara istilah media pembelajaran Pinball ini adalah sebuah papan dimana berisikan beberapa kolom yang nantinya akan dimainkan oleh siswa dengan memantulkan bola untuk menuju kedalam salah satu kolom yang tersedia, didalam kolom tersebut berisikan pertanyaan sesuai dengan mata pelajaran matematika.

Penelitian ini sejalan dengan penelitian yang dilakukan oleh Nuril Milati (2009) dengan judul "Penerapan Pembelajaran Kooperatif Tipe TGT Untuk Meningkatkan Prestasi Belajar Matematika Siswa Kelas V Madrasah Ibtidaiyah Ar-Rahmah Jabung Malang". Hasil penelitian menunjukan bahwa penerapan pembelajaran kooperatif tipe TGT dapat meningkatkan prestasi belajar matematika pada siswa kelas V MI ArRahmah Jabung Malang pada sub pokok bangun datar trapesium. Hal ini menunjukkan $97.14 \%$ siswa 
berhasil mempelajari bangun datar trapesium pada mata pelajaran matematika dan terjadi peningkatan prestasi belajar siswa.

Model pembelajaran TGT berbantu media pinball adalah salah satu tipe atau model pembelajaran kooperatif yang mudah diterapkan, melibatkan aktivitas seluruh peseeta didik tanpa harus ada perbedaan status, melibatkan peran siswa sebagai tutor sebaya dan mengandung unsur permainan dan reinforcement. Aktivitas belajar dengan permainan pinball yang dirancang dalam pembelajaran kooperatif model TGT memungkinkan siswa dapat belajar lebih rileks disamping menumbuhkan tanggung jawab, kejujuran, kerja sama, persaingan sehat dan keterlibatan belajar. Penelitian dilakukan di kelas V SD N 03 Pamutih tahun ajaran 2018-2019. Penggunaan model pembelajaran kooperatif TGT berbantu media pinball diupayakan untuk mengoptimalkan hasil belajar dalam mata pelajaran matematika. Penelitian ini bertujuan untuk mengetahui: (1) pengaruh hasil belajar siswa setelah diberikan model pembelajaran TGT berbantu media pinball.

\section{Metode}

Metode penelitian

Metode penelitian diartikan sebagai cara ilmiah untuk mendapatkan data dengan tujuan dan kegunaan tertentu (Sugiono, 2015:3). Metode penelitian yang akan digunakan pada penelitian ini adalah metode eksperimen. Metode eksperimen merupakan metode penelitian yang digunakan untuk mencari pengaruh treatment (perlakuan) tertentu terhadap yang lain dalam kondisi yang dikendalikan (Sugiyono, 2015:6). Desain penelitian yang digunakan dalam penelitian ini adalah dengan Pre-eksperimental Design dengan model One-Group Pretest-Posttest Design. Design ini dapat di gambarkan sebagai berikut:

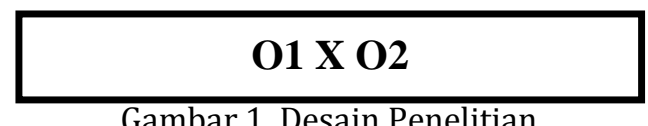

Keterangan :

Gambar 1. Desain Penelitian

$\mathrm{O}_{1}$ : Nilai Pre-test (sebelum diberi perlakuan)

$\mathrm{O}_{2}$ : Nilai Post-test (setelah diberi perlakuan)

$\mathrm{X}$ : Perlakuan pada Model Cooperative Learning Team Games Tournament berbantu media Pinball.

$\mathrm{O}_{2}-\mathrm{O}_{1}$ : pengaruh perlakuan. (Sugiono, 2015:74).

Dalam penelitian dapat diketahui bahwa: a. Variabel (X) yaitu model Cooperative Learning Team Games Tournament Berbantu Media Pinball.b. Variabel (Y) yaitu hasil belajar siswa. Dari penelitian ini adalah hasil belajar siswa kelas V SD Negeri 03 Pamutih yang menggunakan model Cooperative Learning Team Games Tournament Berbantu Media Pinball. Hasil belajar siswa kelas V SD Negeri 03 Pamutih dapat diketahui dengan nilai pretest dan postest.

Penelitian ini dilaksanakan di SD Negeri 03 Pamutih. Alasan memilih SD Negeri 03 Pamutih sebagai tempat penelitian yaitu karena peneliti menemukan permasalahan dengan hasil belajar siswa Matematika yang rendah sehingga peneliti bermaksud untuk memperbaikinya. Penelitian ini dilaksanakan pada semester genap tahun ajaran 2018/2019 pada materi Bangun Ruang kelas V SD Negeri 03 Pamutih.

Teknik pengumpulan data dalam penelitian ini adalah a) Dokumentasi,dokumentasi merupakan catatan peristiwa yang sudah berlalu (Sugiyono, 2016:329). Peneliti membutuhkan dokumentasi sebagai bukti telah diadakan penelitian. Bukti dokumentasi dapat berupa foto-foto kegiatan pembelajaran, hasil lembar siswa maupun data-data kelas V SD Negeri 03 Pamutih. b)Tes, Arikunto (2013:53) menyatakan bahwa Tes adalah alat prosedur yang digunakan untuk mengetahui atau mengukur sesuatu dalam susasana, dengan cara dan aturan-aturan yang sudah ditentukan.Tes ini digunakan untuk mengukur tingkat pemahaman hasil belajar matematika materi bangun ruang pada siswa kelas V SD Negeri 03 Pamutih, c) Observasi, Arikunto (2013:45) menjelaskan bahwa observasi adalah teknik yang dilakukan dengan cara mengadakan pengamatan secara teliti serta pencatatan secara sistematis. Observasi digunakan untuk menguji pengaruh model Team Games Tournament berbantu media Pinball terhadap hasil belajar mata pelajaran Matematika kelas V SD Negeri 03 pamutih.

Analisis instrumen penelitian antara lain: a) Validitas Soal penelitian ini menggunakan validitas soal rumus korelasi product moment dengan menguji cobakan pada kelas V SD N 02 Pamutih. Uji validitas digunakan untuk menghitung instrument yang valid dan tidak valid., b) Reliabilitas Soal, Arikunto (2013: 100) mengatakan "Suatu tes dapat dikatakan mempunyai tingkat kepercayaan yang tinggi jika tes tersebut dapat memberikan hasil yang tetap. Maka reliabilitas tes, berhubungan dengan ketetapan hasil tes". 
Pengujian reliabitas instrumen dapat dilakukan secara eksternal maupun internal. Secara eksternal pengujian dapat dilakukan dengan pretest dan posttest (stability), equivalent, dan gabungan keduanya. Secara internal reliabilitas instrumen dapat diuji dengan menganalisis konsistensi butirbutir yang ada pada instrumen dengan teknik tertentu, c) Taraf Kesukaran, soal yang baik adalah soal yang tidak terlalu mudah dan tidak terlalu sukar, soal yang terlalu mudah tidak memotivasi siswa untuk meningkatkan usaha pemecahannya, sedangkan soal yang terlalu sukar akan menyebabkan siswa menjadi putus asa dan menjadi tidak semangat untuk mencoba lagi karena di luar jangkauannya. Dan d) Daya Pembeda, Arikunto (2013: 226) mengatakan Daya pembeda soal adalah kemampuan sesuatu soal untuk membedakan antara siswa yang berkemampuan tinggi dengan siswa yang berkemampuan rendah. Daya pembeda adalah pengukuran sejauh mana suatu butir soal mampu membedakan siswa yang sudah menguasai kompetensi dengan siswa yang belum atau kurang menguasai kompetensi berdasarkan kriteria tertentu. Semakin tinggi koefisien daya pembeda suatu butir soal, semakin mampu butir soal tersebut membedakan antara siswa kelompok atas dan siswa kelompok bawah yang menguasai kompetensi dengan siswa yang kurang menguasai kompetensi.

Analisis data merupakan suatu cara untuk mengolah data hasil penelitian guna memperoleh suatu kesimpulan, adapun langkah-langkahnya sebagai berikut: a) Uji normalitas, uji normalitas ini digunakan untuk mengetahui apakah sampel dari populasi berdistribusi normal atau tidak. Untuk mengetahui suatu sampel dari populasi yang ada peneliti menggunakan uji liliefors, b) Uji T-test, uji T-test digunakan untuk mengukur peningkatan hasil pretest dan hasil posttest. uji t-test yang digunakan peneliti yaitu Uji Paired Samples t-test adalah uji yang digunakan untuk mengetahui perbedaan hasil belajar pada satu kelompok orang antara sebelum perlakuan dengan sesudah diberi perlakuan. Rumus uji t sebagai berikut:

$$
t=\frac{M d}{\sqrt{\frac{\sum x d^{2}}{N(N-2)}}}
$$

Keterangan :

Md = mean dari perbedaan pretest dan posttet.

$\mathrm{Xd} \quad=$ devisi masing-masing subjek $(\mathrm{d}-\mathrm{Md})$.

$\mathrm{N} \quad=$ Subjek pada sempel.

d.b = ditentukan dengan $\mathrm{N}-1$.

Uji Hipotesis untuk Uji T-test sebagai berikut :

Ho : hasil pretest dan posttest tidak ada pengaruh.

Ha : hasil pretest dan posttest ada pengaruh.

\section{Hasil dan Pembahasan}

Langkah awal dalam melakukan penelitian di SD N 03 Pamutih yaitu, a) meminta izin observasi terhadap pihak sekolah. b) melakukan observasi. c) menganalisis data awal. d) menentukan sampel penelitian. e) menentukan kelas uji coba. f) persiapan perangkat pembelajaran. g) melakukan uji coba instrumen h) melakukan penelitian.

Analisis Data awal (pretest), Uji normalitas digunakan untuk mengetahui sampel berasal dari populasi yang berdistribusi normal atau tidak. Uji normalitas yang digunakan adalah uji Liliefors. nilai L0 sebesar 0,1452 . Untuk $n=30$ dan taraf $5 \%$, berdasarkan tabel nilai kritik uji Lilliefors diperoleh harga Ltabel $=0,161$. Hal ini berarti L0 =0,1452 < Ltabel =0,161. Sehingga kesimpulannya H0 diterima. Artinya sampel berasal dari populasi berdistribusi normal.

Analisis Data Akhir (Posttest), uji normalitas untuk mengetahui sampel berasal dari populasi yang berdistribusi normal atau tidak. Uji normalitas yang digunakan adalah uji Liliefors.nilai L0 sebesar 0,1401. Untuk $\mathrm{n}=30$ dan taraf $5 \%$, berdasarkan tabel nilai kritik uji Lilliefors diperoleh harga Ltabel =0,161. Hal ini berarti $\mathrm{LO}=0,1401<\mathrm{Ltabel}=0,161$. Sehingga kesimpulannya H0 diterima Artinya sampel berasal dari populasi berdistribusi normal

Uji T-test Penelitian ini, uji t-test yang digunakan peneliti yaitu Uji Paired Samples t-test adalah uji yang digunakan untuk mengetahui perbedaan hasil belajar pada satu kelompok orang antara sebelum perlakuan dengan sesudah diberi perlakuan. Mean deviasi sebesar 12,67 dan taraf signifikan 5\% didapatkan ttabel sebesar 2,042 sedangkan thitung sebesar 4,35. Dapat disimpulkan bahwa nilai thitung 4,35 > ttabel 2,042. Jadi H0 ditolak dan Ha diterima artinya bahwa hasil belajar siswa pada mata pelajaran matematika materi bangun ruang sebelum menggunakan model Pembelajaran Team Game Tournament 
(TGT) berbantu Media pinball dan sesudah menggunakan model Pembelajaran Team Game Tournament (TGT) berbantu Media pinball tidak sama

\section{Simpulan dan Saran}

Berdasarkan latar belakang, metode penelitian dan pembahasan, maka peneliti membuat kesimpulan bahwa model Team Games Tournament berbantu Media Pinball Matematika berpengaruh terhadap hasil belajar siswa kelas V SD Negeri 03 Pamutih. Hal ini dibuktikan dengan Hasil uji $t$ test sebesar 4,35 dengan taraf signifikan $\alpha=5 \%$ dan ttabel $=2,042$. Berdasarkan kriteria pengujian apabila diperoleh nilai thitung $\geq$ ttabel Ha diterima atau $4,35 \geq 2,048$, sehingga HO ditolak dan Ha diterima. Jadi, pengaruh peningkatkan hasil belajar siswa setelah diberikan model TGT berbantu media pinball sebesar $23,3 \%$.

Berdasarkan kesimpulan diatas maka saran yang dapat diberikan untuk meningkatkan pembelajaran pada kelas V SD Negeri 03 Pamutih sebagai berikut: a. Model Team Games Tournament berpengaruh terhadap hasil belajar pada peerta didik sehingga pendidik dapat menerapkannya sebagai alternatif model pembelajaran yang dapat meningkatkan hasil belajar siswa, b. Media pinball dapat dimanfaatkan sebagai salah satu alternatif media yang membantu siswa dalam memahami materi matematika bangun ruang, c. Model Team Games Tournament berbantu media pinball memberikan pengaruh yang positif pada siswa sehingga pendidik dapat menerapkannya sebagai salah satu cara dalam pembelajaran yang dapat meningkatkan hasil belajar pesetrta didik, dan d. Hendaknya dalam proses pembelajaran dapat menggunakan media pembelajaran yang tepat agar tercipta suasana belajar yang antusias, aktif, menyenangkan dan efektif sehingga diharapkan hasil belajar siswa dapat maksimal dan meningkat.

\section{Daftar Rujukan}

Arikunto, Suharsimi. 2013. Dasar-Dasar Evaluasi Pendidikan, Jakarta :Bumi Aksara.

Aryun Nailun Nasikhah, Florentina Widihastrini, Susilo Tri Widodo. 2016. Pengembangan Game Education Pembelajran Pkn Materi Menghargai Keputusan Bersama Kelas V SD. Jurnal Kreatif September 2016.

Azhar Arsyad. 2014. Media Pembelajaran. Jakarta : Raja Grafindo Persada.

Azizah, Purnomo, dan Reffiane. 2018. Pengaruh Model TGT Berbantu Media Utama Terhadap Hasil Belajar Matematika Ditinjau Dari Aktivitas Belajar Siswa Kelas V SD. Jurnal Sekolah (JS). Vol 2 (4) September 2018, hlm. 329-335.

Depdiknas. 2001. Kamus Besar Bahasa Indonesia. Jakarta : Balai Pustaka.

Heruman. 2016. Model Matematika di Sekolah Dasar. Bandung: Remaja Rosdakarya.

Huda, Miftahul. 2013. Model-Model Pengajaran Dan Pembelajaran. Yogyakarta: Pustaka Pelajar.

Kurniasih dan Berlin. 2017. Ragam Pengembangan Model Pembelajaran, Jakarta: Kata Pena.

Putra Fredi Ganda. 2015. Eksperimentasi Model Pembelajaran Kooperatif Tipe Teams Games Tournament (TGT) Berbantuan Softwere Cabri 3d di Tinjau Dari Kemampuan Koneksi Mateamtis Siswa. AlJabar: Jurnal Pendidikan Matematika Vol. 6, No. 2, 2015, Hal 143 - 153.

Qalbi, Mantasiah, Jufri dan Yusri, 2017. Efektivitas Model Pembelajaran Kooperatif Tipe Team GamesTournaments Dalam Ketrampilan Menulis Bahsa Jerman Siwswa Kelas XII IPA SMA Negeri 1 Bontonompo Kabupaten Gowa. Jurnal Penelitian Pendidikan INSANI, Volume 20, Nomor 1, Juni 2017, hlm. 67-72.

Sabrina Ridha, Fauzi, M. Yamin. 2017. Faktor-faktor Penyebab Rendahnya Motivasi Belajar Siswa Dalam Proses Pembelajaran Matematika Di Kelas V SD Negeri Garot Geucu Aceh Barat. Jurnal Ilmiah Pendidikan Guru Sekolah Dasar FKIP Unsyiah Volume 2 Nomor 4, 108-118.

Sari Erma Andhika. 2011. Penerapan Model TGT (Team Games Tournament) Sebagai Upaya Meeningkatkan Kemampuan Bercira Siswa Kelas X-B SMA Ma'arif Pandaan-Pasuruan Tahun Ajaran 2008/2009. Jurnal Artikulasi Vol.12 No.2. 
Shoimin,Aris. 2014. Model Pembelajaran Inovatif Dalam Kurikulum 2013. Yogyakarta: Ar-Ruzz Media.

Slameto. 2013. Belajar Dan Faktor-Faktor yang Mempengaruhinya. Jakarta: Rineka Cipta.

Sugiyono. 2015. Metode Penelitian Pendidikan Pendekatan Kuantitatif, Kualitatif, danR\&D. Bandung: Alfabeta.

Suhendri Heri. 2011. Pengaruh Kecerdasan Matematis-Logis dan Kemandirian Belajar Terhadap Hasil Belajar Matematika. Jurnal Formatif 1(1): 29-39 ISSN: 2088-351X.

Sundayana, Rostina. 2015. Media dan Alat Peraga Dalam Pembelajaran Matematika. Bandung: Alfabeta.

Suprijono, Agus. 2014. Cooperative Learning. Yogyakarta: Pustaka Pelajar.

Susanto, Ahmad. 2016. Teori Belajar dan Pembelajaran di Sekolah Dasar, Jakarta: Prenadamedia Group.

Widyawati Riana Lilis, Suryadi Budi Utomo, dan Sulistyo Saputro. 2016. Penerapan Model Pembelajaran Teams Games Tournaments (Tgt) Dilengkapi Flash Chemquiz Untuk Meningkatkan Minat Dan Prestasi Belajar Materi Hidrokarbon Pada Siswa Kelas X-8 Sma Negeri 3 Boyolali Tahun Pelajaran 2015/2016. Jurnal Pendidikan Kimia (JPK), Vol. 5 No. 4 Tahun 2016 Program Studi Pendidikan Kimia Universitas Sebelas Maret.

Zuhri Saputra Hadi. 2016. Pengembangna Media Smart Pinball Pada Pembelajaran Tematik Tema Makananku sehat dan Bergizi Kelas IV Sekolah Dasar. Fakultas Keguruan dan Ilmu Pendidikan Universitas Muhammadiyah Malang. 